\title{
EFFECT OF $\mathrm{MnO}_{2}$ ON THE ELECTRICAL PROPERTIES OF 0.96KNNT-0.04BNZ LEAD-FREE PIEZOELECTRIC CERAMICS
}

\author{
WENQIN LUO, ${ }^{\# Z O N G Y A N G ~ S H E N ~}$
}

Energy Storage and Conversion Ceramic Materials Engineering Laboratory of Jiangxi Province, China National Light Industry Key Laboratory of Functional Ceramic Materials, School of Materials Science and Engineering, Jingdezhen Ceramic Institute, Jingdezhen 333403, China

"E-mail: shenzongyang@163.com

Submitted June 6, 2019; accepted August 6, 2019

\begin{abstract}
Keywords: Lead-free ceramics, Piezoelectric properties, $\mathrm{KNN}, \mathrm{MnO}_{2}$ dopinge
$0.96\left(\mathrm{~K}_{0.49} \mathrm{Na}_{0.51}\right)\left(\mathrm{Nb}_{0.97} \mathrm{Ta}_{0.03}\right) \mathrm{O3}-0.04 \mathrm{Bi}_{0.5} \mathrm{Na}_{0.5} \mathrm{ZrO}_{3}+x \mathrm{~mol} . \% \mathrm{MnO}_{2}\left(0.96 \mathrm{KNNT}-0.04 \mathrm{BNZ}+x \mathrm{~mol} . \% \mathrm{MnO}_{2}, x=0,0.1\right.$, $0.2,0.4,0.6,0.8)$ lead-free piezoelectric ceramics were prepared via conventional solid state method. The effect of $\mathrm{MnO}_{2}$ doping content on the structure and electrical properties of 0.96KNNT-0.04BNZ ceramics was investigated. All samples had pure perovskite structure with coexistence of orthorhombic and tetragonal phases at room temperature. The 0.96KNNT$0.04 \mathrm{BNZ}+0.2 \mathrm{~mol} . \% \mathrm{MnO}_{2}$ ceramic sample exhibited enhanced piezoelectric constant $\left(d_{33}=330 \mathrm{pC} / \mathrm{N}\right)$ and planar electromechanical coupling coefficient $\left(k_{p}=38.8 \%\right)$. In addition to other optimized electrical properties such as medium high dielectric permittivity $\left.\left(\left(\varepsilon_{33}^{T}\right)\right) \varepsilon_{0}=1370\right)$ and mechanical quality factor $\left(Q_{m}=135\right)$, relatively low dielectric loss $(\tan \delta=2.4 \%)$ and high Curie temperature $\left(T_{c}=305{ }^{\circ} \mathrm{C}\right)$, this ceramic sample should be a promising lead-free alternative to toxic leadbased piezoelectric materials.
\end{abstract}

\section{INTRODUCTION}

Lead contained piezoelectric materials, typically represented by $\mathrm{Pb}(\mathrm{Zi}, \mathrm{Ti}) \mathrm{O}_{3} \quad(\mathrm{PZT})$ and $\mathrm{Pb}(\mathrm{Mg}, \mathrm{Nb})$ $\mathrm{O}_{3}-\mathrm{PbTiO}_{3}$ (PMN-PT), have been widely applied in sensors, actuators, and transducers due to their excellent electrical properties [1-3]. However, the toxic element $\mathrm{Pb}$ is harmful to the environment and human health, and the legislation will be enacted to reduce the $\mathrm{Pb}$ content in electronics and other consumer products in the near future. Therefore, developing lead-free piezoelectric ceramics has attracted much interest because of rising environmental and social concerns [4-6].

$(\mathrm{K}, \mathrm{Na}) \mathrm{NbO}_{3}(\mathrm{KNN})$-based ceramics are considered as one of the most promising lead-free alternatives to replace lead-based ceramics and have been extensively studied in the past decade [7-17]. One crucial studying direction in KNN-based ceramics is to establish the orthorhombic-tetragonal $(\mathrm{O}-\mathrm{T})$ phase boundary near room temperature by A- and/or B-site modification to enhance piezoelectric properties. For example, A-site $\mathrm{Li}^{+}, \mathrm{B}$-site $\mathrm{Ta}^{5+}$ and $\mathrm{Sb}^{5+}$ modified $\mathrm{KNN}$ with O-T phase boundary around room temperature is reported to having enhanced piezoelectric constant $\mathrm{d}_{33}$ of $\sim 300 \mathrm{pC} / \mathrm{N}$ [7-12]. Moreover, a new rhombohedraltetragonal (R-T) phase boundary has been developed in $(\mathrm{Bi}, \mathrm{Na}, \mathrm{K}) \mathrm{ZrO}_{3}$ modified $\mathrm{KNN}$-based ceramics, whose piezoelectric properties are reported to be comparable to those of some commercialized PZT ceramics [13, 14].
Actually, we also designed a lead-free $(1-x)\left(\mathrm{K}_{0.49} \mathrm{Na}_{0.51}\right)$ $\left(\mathrm{Nb}_{0.97} \mathrm{Ta}_{0.03}\right) \mathrm{O}_{3}-x \mathrm{Bi}_{0.5} \mathrm{Na}_{0.5} \mathrm{ZrO}_{3}$ system in our previous work, and an enhanced $\mathrm{d}_{33}$ of $317 \mathrm{pC} / \mathrm{N}$ was obtained at the composition $x=0.04$ accompanied by a high Curie temperature $\left(T_{c}=310{ }^{\circ} \mathrm{C}\right)$ [18]. However, other properties of this ceramic sample such as low mechanical quality factor and relatively high dielectric loss need to be further optimized from the viewpoint of commercialized usage.

On the other hand, manganese has been widely reported to improve electrical properties of piezoelectric ceramics, regardless of the introduction form of $\mathrm{MnCO}_{3}$ or $\mathrm{MnO}_{2}$, whether or not manganese enters the lattice in a stoichiometric ratio or remains at grain boundary in an impurity form $[19,20]$. Therefore, in the current research, we choose $0.96\left(\mathrm{~K}_{0.49} \mathrm{Na}_{0.51}\right)\left(\mathrm{Nb}_{0.97} \mathrm{Ta}_{0.03}\right) \mathrm{O}_{3}$ $-0.04 \mathrm{Bi}_{0.5} \mathrm{Na}_{0.5} \mathrm{ZrO}_{3}(0.96 \mathrm{KNNT}-0.04 \mathrm{BNZ})$ as the base material, while manganese dioxide $\left(\mathrm{MnO}_{2}\right)$ is introduced with the target to optimize the piezoelectric properties.

\section{EXPERIMENTAL}

Raw materials of analytical reagent grade $\mathrm{K}_{2} \mathrm{CO}_{3}$, $\mathrm{Na}_{2} \mathrm{CO}_{3}, \mathrm{Nb}_{2} \mathrm{O}_{5}, \mathrm{Ta}_{2} \mathrm{O}_{5}, \mathrm{Bi}_{2} \mathrm{O}_{3}, \mathrm{ZrO}_{2}$ and $\mathrm{MnO}_{2}$ from Sinopharm Chemical Reagent Co. Ltd., Shanghai, China were combined in our system $0.96\left(\mathrm{~K}_{0.49} \mathrm{Na}_{0.51}\right)$ $\left(\mathrm{Nb}_{0.97} \mathrm{Ta}_{0.03}\right) \mathrm{O}_{3}-0.04 \mathrm{Bi}_{0.5} \mathrm{Na}_{0.5} \mathrm{ZrO}_{3}+x$ mol. \% $\mathrm{MnO}_{2}$ (0.96KNNT-0.04BNZ $+x$ mol. $\% \mathrm{MnO}_{2}, x=0,0.1,0.2$, 
$0.4,0.6,0.8)$ to prepare ceramic sample by conventional processing route. The raw materials were weighed for each composition and mixed for $24 \mathrm{~h}$ in zirconia ball mill at a speed of $120 \mathrm{rpm}$ using absolute ethanol medium. The mixture was calcined at $850{ }^{\circ} \mathrm{C}$ for $4 \mathrm{~h}$ and then ground again for $24 \mathrm{~h}$. After drying, the polyvinyl alcohol solution (PVA, $5 \mathrm{wt}$ \%) as a binder was added to the calcined powders for granulation. Disks $(13 \mathrm{~mm}$ in diameter by $1.2 \mathrm{~mm}$ thick) were formed by pre-pressing at $100 \mathrm{MPa}$, and then followed by a cold isostatic pressing. After preheating for $2 \mathrm{~h}$ at $650{ }^{\circ} \mathrm{C}$ to remove PVA binders, the pellets were sintered for $3 \mathrm{~h}$ between $1090{ }^{\circ} \mathrm{C}$ and $1130{ }^{\circ} \mathrm{C}$ in an ambient atmosphere with a heating rate of $5^{\circ} \mathrm{C} \cdot \mathrm{min}^{-1}$, and then furnace cooling to room temperature.

X-ray diffraction (XRD, D8-Advance, $\mathrm{CuK}_{\alpha}$ radiation) was applied to analyze the phase structure of polished sintered ceramic samples. Scanning electron microscope (SEM, JSM-6700F) was used to observe the microstructural characteristics of polished and thermally etched surface of sintered ceramics. For electrical measurements, both sides of the specimens were polished and painted with silver pastes, and then fired for $20 \mathrm{~min}$ at $800{ }^{\circ} \mathrm{C}$ to form electrodes. Weakfield dielectric constant and loss at $1 \mathrm{kHz}$ as a function of temperature from room temperature to $500{ }^{\circ} \mathrm{C}$ were measured by a precision impedance analyzer (HP4294A, Agilent), joining a controlled-temperature cell. For piezoelectric measurements, the samples were poled at $130{ }^{\circ} \mathrm{C}$ for $30 \mathrm{~min}$ in silicone oil bath applied with an electric field of $30 \sim 40 \mathrm{kV} \cdot \mathrm{cm}^{-1}$. A quasi-static $\mathrm{d}_{33}$ meter (ZJ-3A) was used to measure piezoelectric constant $\mathrm{d}_{33}$. The planar electromechanical coupling coefficient was determined by resonance method based on IEEE standard on piezoelectricity [21]. Room temperature polarization-electric field (P-E) loops were observed on a radiant precision workstation (TRek model 609B) using standard Sawyer and Tower circuits.

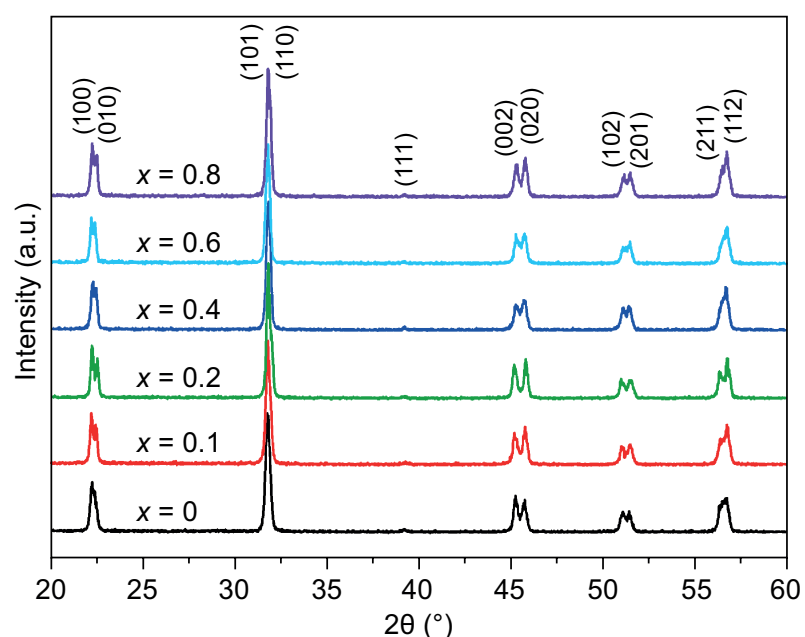

Figure 1. XRD patterns of $0.96 \mathrm{KNNT}-0.04 \mathrm{BNZ}+x \mathrm{~mol}$. $\%$ $\mathrm{MnO}_{2}$ ceramics.

\section{RESULTS AND DISCUSSION}

As seen from the XRD patterns of $0.96 \mathrm{KNNT}-$ $-0.04 \mathrm{BNZ}+x$ mol. $\% \mathrm{MnO}_{2}$ ceramics shown in Figure 1 , all ceramic samples are indexed pure perovskite structure, and no impurities can be observed within the detection limit of XRD technique. The splitting diffraction peaks (002) and (020) near $45^{\circ}$ are approximately equal in height, indicating that all samples are polymorphic phase transition (PPT) structure with coexistence of orthogonal-tetragonal phases [9, 10]. Meanwhile, no obvious diffraction peak shifting is observed with the increase of $\mathrm{MnO}_{2}$ doping content, which should be related to low doping content of $\mathrm{MnO}_{2}$ $\left(<0.8\right.$ mol. \%) and similar ionic radius between $\mathrm{Mn}^{4+}$ $\left(r_{i}=0.053 \mathrm{~nm}, \mathrm{CN}=6\right)$ and $\mathrm{Nb}^{5+}\left(r_{i}=0.064 \mathrm{~nm}, \mathrm{CN}=\right.$ =6) [22].

Figure 2 shows the piezoelectric constant $\mathrm{d}_{33}$, planar electromechanical coupling coefficient $\mathrm{k}_{\mathrm{p}}$ and mechanical quality factor $Q_{m}$ of $0.96 \mathrm{KNNT}-0.04 \mathrm{BNZ}+$ $+x$ mol. $\% \mathrm{MnO}_{2}$ ceramics. With the increase of $x$ value, the $d_{33}$ and $k_{p}$ first slightly increase and then drop down, presenting peak values of $330 \mathrm{pC} / \mathrm{N}$ and $38.8 \%$, respectively for the composition with $x=0.2$. However, the $Q_{m}$ is found to increase monotonously with the increase of $\mathrm{MnO}_{2}$ doping content. This phenomenon may be due to the hard doping effect of $\mathrm{MnO}_{2}$. The replacement of $\mathrm{Nb}^{5+}$ by $\mathrm{Mn}^{4+}$ in B-site will produce oxygen vacancies, and the oxygen vacancy will make the domain wall movement more difficult, thus increasing the $Q_{m}$ of the ceramic sample [23].

The dielectric permittivity and loss $\tan \delta$ of 0.96 $\mathrm{KNNT}-0.04 \mathrm{BNZ}+x \mathrm{~mol} . \% \mathrm{MnO}_{2}$ ceramics are shown in Figure 3. It can be seen that the variation tendency of with $\mathrm{MnO}_{2}$ doping content is the same as that of $\mathrm{d}_{33}$ and $k_{\mathrm{p}}$, showing a peak value of 1370 when $x=0.2$. The enhanced dielectric permittivity should make some contribution to the increase of piezoelectric constant according to the basic theory of ferroelectrics [24]. The dielectric loss $\tan \delta$ shows a reverse trend to dielectric constant, having a lowest value of $2.4 \%$ for the ceramic sample with $x=0.2$.

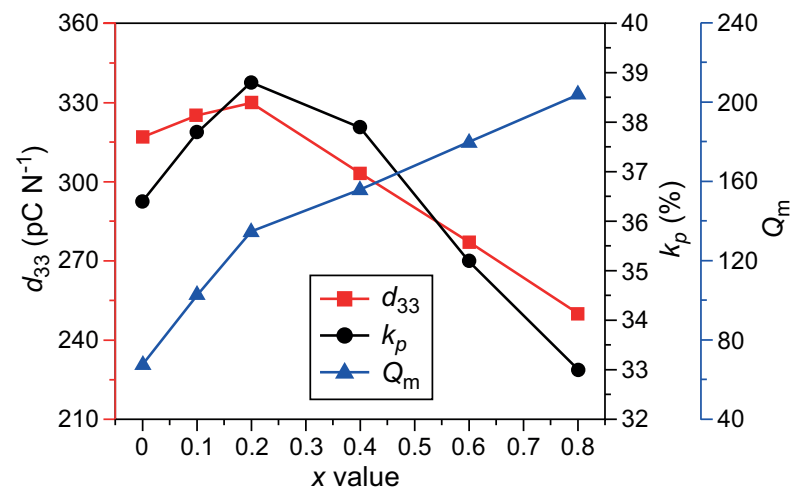

Figure 2. The $d_{33}, k_{p}$ and $Q_{\mathrm{m}}$ of $0.96 \mathrm{KNNT}-0.04 \mathrm{BNZ}+x \mathrm{~mol} . \%$ $\mathrm{MnO}_{2}$ ceramics as a function of $x$ values. 


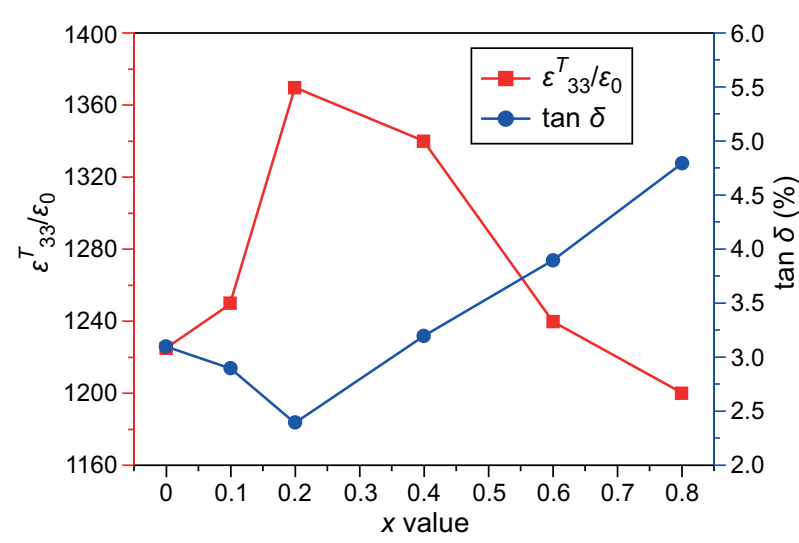

Figure 3. The $\left(\varepsilon_{33}^{T} / \varepsilon_{0}\right.$ and $\tan \delta$ of $0.96 \mathrm{KNNT}-0.04 \mathrm{BNZ}+x$ mol. $\%$ $\mathrm{MnO}_{2}$ ceramics as a function of $x$ values.

Figure 4 gives the P-E hysteresis loops of 0.96 KNNT- $0.04 \mathrm{BNZ}+x \tan$ mol. $\tan \% \mathrm{MnO}_{2}$ ceramics. All ceramics have well saturated hysteresis loop under an applied electric field of $40 \mathrm{kV} \cdot \mathrm{cm}^{-1}$. Basically, the remnant polarization $P_{\mathrm{r}}$ slightly decreases, while the coercive field $E_{\mathrm{c}}$ increases with the increase of $\mathrm{MnO}_{2}$ doping content, which may also be related to the hard doping effect induced by $\mathrm{Mn}$ addition.

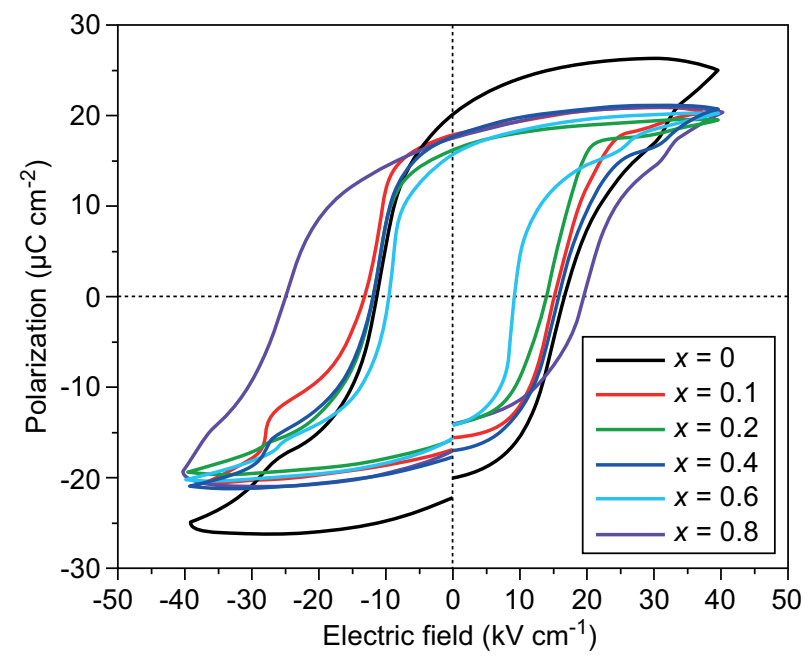

Figure 4. $P-E$ hysteresis loops of $0.96 \mathrm{KNNT}-0.04 \mathrm{BNZ}+$ $+x$ mol. $\% \mathrm{MnO}_{2}$ ceramics.

The temperature dependent dielectric constant of $0.96 \mathrm{KNNT}-0.04 \mathrm{BNZ}+x$ mol. $\% \mathrm{MnO}_{2}$ ceramics is shown in Figure 5. It can be seen that all ceramic samples undergo two different phase transitions corresponding to the orthorhombic-tetragonal $\left(T_{\mathrm{o-t}}\right)$ and tetragonal-cubic $\left(T_{\mathrm{c}}\right)$ respectively $[25,26]$. With the increase of $\mathrm{MnO}_{2}$ doping content, the $\mathrm{T}_{\mathrm{c}}$ can be detected shifting very slightly towards lower temperature, indicating that $\mathrm{Mn}^{4+}$ should incorporate into B-site of perovskite lattice. However, according to the inset of Figure 5, the $T_{0-1}$ around room temperature is almost the same in spite of different $\mathrm{MnO}_{2}$ addition. For the $0.96 \mathrm{KNNT}-0.04 \mathrm{BNZ}$ +0.2 mol. $\% \mathrm{MnO}_{2}$ ceramic sample with optimized piezoelectric properties, a relatively high $T_{\mathrm{c}}$ of $305^{\circ} \mathrm{C}$ is obtained promising for practical applications as leadfree candidate ceramic materials.

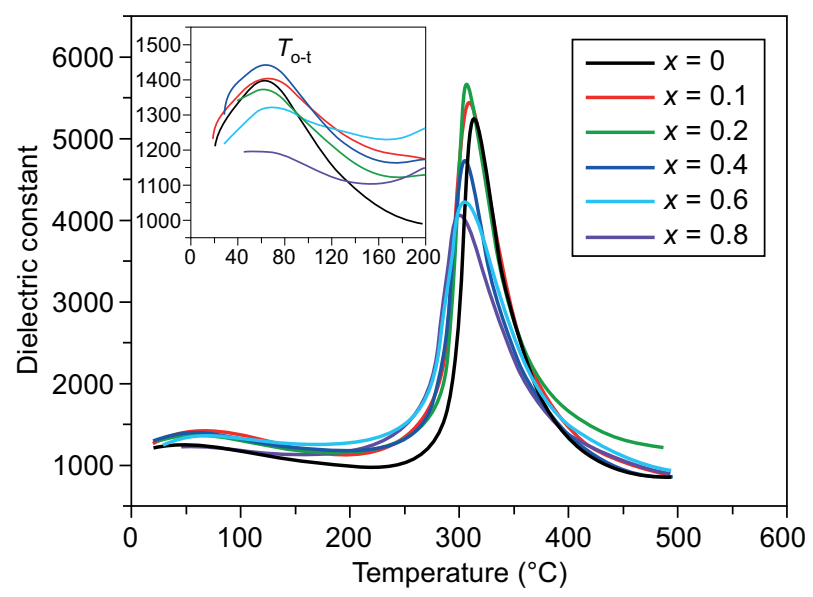

Figure 5. Temperature dependent dielectric constant of 0.96 KNNT-0.04BNZ $+x$ mol. $\% \mathrm{MnO}_{2}$ ceramics. The inset shows an expanded view from room temperature to $\sim 180{ }^{\circ} \mathrm{C}$.

\section{CONCLUSIONS}

In this work, the effect of $\mathrm{MnO}_{2}$ addition on the structure and electrical properties of $0.96 \mathrm{KNNT}-$ $0.04 \mathrm{BNZ}$ ceramics was investigated. $\mathrm{Mn}^{4+}$ should be incorporated into B-site of perovskite lattice, and can enhance dielectric and piezoelectric properties of the ceramics within a certain doping level. The $0.96 \mathrm{KNNT}-$ $0.04 \mathrm{BNZ}+0.2 \mathrm{~mol} . \% \mathrm{MnO}_{2}$ ceramic sample shows optimized properties as follows: $d_{33}=330 \mathrm{pC} / \mathrm{N}, k_{p}=38.8 \%$, $Q_{\mathrm{m}}=135,=1370, \tan \delta=2.4 \%, P_{r}=19.5 \mu \mathrm{C} \mathrm{cm}^{-2}, E_{\mathrm{c}}=$ $=13.9 \mathrm{kV} \cdot \mathrm{cm}^{-1}$ and $T_{\mathrm{c}}=305^{\circ} \mathrm{C}$, providing a good leadfree candidate ceramics for piezoelectric applications.

\section{Acknowledgments}

This work was financially supported by National Natural Science Foundation of China (61671224) and Science Foundation of Jiangxi Provincial Education Department of China (GJJ160919).

\section{REFERENCES}

1. Jaffe B., Cook W. R., Jaffe H. (1971). Piezoelectric Ceramics, Academic, New York.

2. Shung K. K., Cannata J. M., Zhou Q. F. (2007): Piezoelectric materials for high frequency medical imaging applications: A review. Journal of Electroceramics, 19, 139-145. Doi: 10.1007/s10832-007-9044-3 
3. Zhang S., Li F., Jiang X., Kim J., Luo J., Geng X. (2015): Advantages and Challenges of Relaxor- $\mathrm{PbTiO}_{3}$ Ferroelectric Crystals for Electroacoustic Transducers A Review. Progress in Materials Science, 68, 1-66. Doi: 10.1016/j.pmatsci.2014.10.002

4. Saito Y., Takao H., Tani T., Nonoyama T., Takatori K., Homma T., Nagaya T., Nakamura M. (2004): Lead-free piezoceramics. Nature, 432, 84-87. Doi: 10.1038/nature 03028

5. Rödel J., Li J. F. (2018): Lead-free piezoceramics: Status and perspectives. MRS Bulletin, 43, 576-580. Doi: 10.1557/ mrs.2018.181

6. Bell A. J., Deubzer O. (2018): Lead-free piezoelectrics-The environmental and regulatory issues. MRS Bulletin, 43, 581-587. Doi: $10.1557 / \mathrm{mrs} .2018 .154$

7. Dai Y., Zhang X., Zhou G. (2007): Phase transitional behavior in $\mathrm{K}_{0.5} \mathrm{Na}_{0.5} \mathrm{NbO}_{3}-\mathrm{LiTaO}_{3}$ ceramics. Applied Physics Letters, 90, 262903. Doi: 10.1063/1.2751607

8. Akdogan E. K., Kerman K., Abazari M., Safari A. (2008): Origin of high piezoelectric activity in ferroelectric $\left(\mathrm{K}_{0.44} \mathrm{Na}_{0.52} \mathrm{Li}_{0.04}\right) \mathrm{Nb}_{0.84} \mathrm{Ta}_{0.1} \mathrm{Sb}_{0.06} \mathrm{O}_{3}$ ceramics. Applied Physics Letters, 92, 112908. Doi: 10.1063/1.2897033

9. Shen Z. Y., Zhen Y., Wang K., Li J. F. (2009): Influence of Sintering Temperature on Grain Growth and Phase Structure of Compositionally Optimized High-Performance $\mathrm{Li} / \mathrm{Ta}-$ Modified $(\mathrm{Na}, \mathrm{K}) \mathrm{NbO}_{3}$ Ceramics. Journal of the American Ceramics Society, 92, 1748-1752. Doi: 10.1111/j.1551-2916.2009.03128.x

10. Zuo R., Fu J., Lv D. (2009): Phase Transformation and Tunable Piezoelectric Properties of Lead-Free $\left(\mathrm{Na}_{0.52} \mathrm{~K}_{0.48-x} \mathrm{Li}_{x}\right)$ $\left(\mathrm{Nb}_{1-x-y} \mathrm{Sb}_{y} \mathrm{Ta}_{x}\right) \mathrm{O}_{3}$ System. Journal of the American Ceramics Society, 92, 283-285. Doi: 10.1111/j.1551-2916.2008. 02871.x

11. Wang K., Li J. F. (2010): Domain engineering of leadfree Li-modified $(\mathrm{K}, \mathrm{Na}) \mathrm{NbO}_{3}$ polycrystals with highly enhanced piezoelectricity. Advanced Functional Materials, 20, 1924-1929. Doi: 10.1002/adfm.201000284

12. Gao Y., Zhang J., Qing Y., Tan Y., Zhang Z., Hao X. (2011): Remarkably Strong Piezoelectricity of Lead-Free $\left(\mathrm{K}_{0.45} \mathrm{Na}_{0.55}\right)_{0.98} \mathrm{Li}_{0.02}\left(\mathrm{Nb}_{0.77} \mathrm{Ta}_{0.18} \mathrm{Sb}_{0.05}\right) \mathrm{O}_{3}$ Ceramic. Journal of the American Ceramics Society, 94, 2968-2973. Doi: 10.1111/j.1551-2916.2011.04468.x

13. Wang X., Wu J., Xiao D., Zhu J., Cheng X., Zheng T., Zhang B., Lou X., Wang X. (2014): Giant piezoelectircity in potassium-sodium niobate lead-free ceramics. Journal of the American Chemistry Society, 136, 2905-2910. Doi: 10.1021/ja500076h

14. Zheng T., Wu H., Yuan Y., Lv X., Li Q., Men T., Zhao C., Xiao D., Wu J., Wang K., Li J.F., Gu Y., Zhu J., Pennycook S.J. (2017): The structural origin of enhanced piezoelectric performance and stability in lead free ceramics. Energy \& Environmental Science, 10, 528-537. Doi: 10.1039/ C6EE03597C
15. Zhang M., Wang K., Du Y., Dai G., Sun W., Li G., Hu D., Thong H.C., Zhao C., Xi X., Yue Z., Li J.F. (2017): High and Temperature-Insensitive Piezoelectric Strain in Alkali Niobate Lead-free Perovskite. Journal of the American Chemistry Society, 139, 3889-3895. Doi: 10.1021/jacs. $7 \mathrm{~b} 00520$

16. Li P., Zhai J., Shen B., Zhang S., Li X., Zhu F., Zhang X. (2018): Ultrahigh Piezoelectric Properties in Textured $(\mathrm{K}, \mathrm{Na}) \mathrm{NbO}_{3}$-Based Lead-Free Ceramics. Advanced Materials, 30, 1705171. Doi: 10.1002/adma.201705171

17. Li P., Huan Y., Yang W., Zhu F., Li X., Zhang X., Shen B., Zhai J. (2019): High-performance potassium-sodium niobate lead-free piezoelectric ceramics based on polymorphic phase boundary and crystallographic texture. Acta Materialia, 165, 486-495. Doi: 10.1016/j.actamat.2018. 12.024

18. Shen W., Shen Z. Y., Li Y., Wang Z., Liu H. (2015): Structure and Electrical Properties of $(1-x)\left(\mathrm{K}_{0.49} \mathrm{Na}_{0.51}\right)$ $\left(\mathrm{Nb}_{0.97} \mathrm{Ta}_{0.03}\right) \mathrm{O}_{3}-x \mathrm{Bi}_{0.5} \mathrm{Na}_{0.5} \mathrm{ZrO}_{3}$ Lead-free Piezoelectric Ceramics. Journal of Synthetic Crystals, 44, 2793-2797.

19. Wang X., Liang P., Chao X., Yang Z. (2015): Dielectric Properties and Impedance Spectroscopy of $\mathrm{MnCO}_{3}$ Modified $\left(\mathrm{Ba}_{0.5} \mathrm{Ca}_{015}\right)\left(\mathrm{Zr}_{01} \mathrm{Ti}_{0.9}\right) \mathrm{O}_{3}$ Lead-Free Ceramics. Journal of the American Ceramics Society, 98, 1506-1514. Doi: $10.1111 /$ jace.13481

20. Chen L., Fan H., Zhang S. (2017): Investigation of $\mathrm{MnO}_{2}$ doped $(\mathrm{Ba}, \mathrm{Ca}) \mathrm{TiO}_{3}$ lead-free ceramics for high power piezoelectric applications. Journal of the American Ceramics Society, 100, 3568-3576. Doi: 10.1111/jace.14894

21. Meeker T. R. (1996): Publication and proposed revision of ANSI/IEEE standard 176-1987. IEEE Transactions on Ultrasonics Ferroelectrics and Frequency Control, 43(5), 717-772.

22. Shannon R. (1976): Revised effective ionic radii and systematic studies of interatomic distances in halides and chalcogenides. Acta Crystallographica Section A, 32, 751-767. Doi: 10.1107/S0567739476001551

23. Yao F., Zhang M., Wang K., Zhou J., Chen F., Xu B., Li F., Shen Y., Zhang Q., Gu L., Zhang X., Li J. F. (2018): Refreshing Piezoelectrics: Distinctive Role of Manganese in Lead-Free Perovskites. ACS Applied Materials \& Interfaces, 10, 37298-37306. Doi: 10.1021/acsami.8b14958

24. Damjanovic D. (1998): Ferroelectric, dielectric and piezoelectric properties of ferroelectric thin films and ceramics. Reports on Progress in Physics, 61, 1267-1324. Doi: 10.1088/0034-4885/61/9/002

25. Shirane G., Newnham R., Pepinsky R. (1954): Dielectric Properties and Phase Transitions of $\mathrm{NaNbO}_{3}$ and $(\mathrm{Na}, \mathrm{K})$ $\mathrm{NbO}_{3}$. Physics Review, 96, 581-588. Doi: 10.1103/PhysRev. 96.581

26. Shen Z. Y., Li Y., Jiang L., Li R., Wang Z., Hong Y., Liao R. (2011): Phase transition and electrical properties of LiNbO${ }_{3}$-modified $\mathrm{K}_{0.49} \mathrm{Na}_{0.51} \mathrm{NbO}_{3}$ lead-free piezoceramics. Journal of Materials Science: Materials in Electronics, 22, 1071-1075. Doi: 10.1007/s10854-010-0261-1 